Available online on 15.01.2017 at http://iddtonline.info
noncommercial use, provided the original work is properly cited

Research Article

\title{
FORMULATION, DEVELOPMENT AND CHARACTERIZATION OF SOLID LIPID NANOPARTICLES OF GEMCITABINE HYDROCHLORIDE
}

\author{
Momin Shahanoor ${ }^{* 1}$, Khan Shadab ${ }^{1}$, Ghadge DM ${ }^{2}$, Bhise $\mathrm{KS}^{1}$ \\ ${ }^{\mathbf{1}}$ Department of Pharmaceutics, M.C.E. Society's Allana College of Pharmacy, Pune-411001, Maharashtra, India \\ ${ }^{2}$ Department of Pharmaceutics, Gourishankar institute of pharmaceutical Education and Research, Limb, Satara, (MS), India
}

\section{ABSTRACT}

Gemcitabine Hydrochloride is a BCS class III drug of choice in the treatment of cancer, as a single or in combination chemotherapy. However, its bioavailability is a major concern due to its short half-life. Solid lipid nanoparticles (SLN) of Gemcitabine Hydrochloride were prepared to enhance its bioavailability, hence anticancer activity. The Quality by Design approach was applied for the formulation of SLN. The Randomized $3^{2}$ factorial design was used with responses of particle size and $\%$ entrapment efficiency (\% EE). The optimized batch of Gemcitabine Hydrochloride loaded SLN containing 1gm of GMS as solid lipid, 1gm of Tween80: Sodium Taurocholate as surfactant: co-surfactant and $5 \mathrm{mg}$ of Gemcitabine Hydrochloride was prepared by high shear homogenization method followed by Probe sonication for $15 \mathrm{~min}$ to form nanoparticulate SLN dispersion. The Optimized batch of Gemcitabine Hydrochloride loaded SLN that exhausted mean particle size of $126.1 \mathrm{~nm}$, zeta potential $-28.6 \mathrm{mV}$ and $\% \mathrm{EE} 74.83 \%$ respectively. SEM studies revealed three-dimensional nature of SLN with a slightly rough surface. DSC, results exhibited entrapment of Gemcitabine Hydrochloride in SLN. The optimized batch of SLN was evaluated for in-vitro \% drug release using cellulose membrane dialysis bags for $24 \mathrm{hrs}$ and showed $63.13 \% \mathrm{CDR}$ at $24 \mathrm{hrs}$. Anticancer cell line studies were also performed in human lung cancer cell line (A-549). It concludes that Gemcitabine Hydrochloride loaded Solid lipid Nanoparticles was successfully formulated and evaluated to sustain the drug release by bypassing the first pass metabolism.

Keywords: Gemcitabine Hydrochloride, SLN, QbD, High shear homogenization, anticancer activity.

\section{Article Info}

Received 02 Nov 2016; Review Completed 14 Dec 2016; Accepted 15 Dec 2016, Available online 15 Jan 2017

Cite this article as:

Momin S, Khan S, Ghadage DM, Bhise KS, Formulation, development and characterization of solid lipid nanoparticles of gemcitabine hydrochloride, Journal of Drug Delivery and Therapeutics. 2017; 7(1):1-12 DOI: http://dx.doi.org/10.22270/jddt.v7i1.1349

*Corresponding Author's Email: shahanoormomin@gmail.com

\section{INTRODUCTION:}

Numerous psychological and pathological factors concur in the gradual advancement of the disease, thus progressing in many cases to death. Even though death represents an extreme outcome in the pathology, food contaminants, besides environmental and chemical factors contribute to the development of new cases of cancer each year and an ever-increasing number of patients are necessarily subjected to therapeutic protocols. For this reason, researchers have been focusing their attention on the investigation of novel innovative drug delivery of anti-cancer drug, in order to improve the quality of standard chemotherapy. Gemcitabine (2'.2' difluoro deoxycytidine) is a fluorinated nucleoside analog of cytosine arabinoside (Ara-C) known for potential antitumor effects and radiation sensitization ${ }^{1-2}$. Mainly it is used as a drug of choice for various cancers such as pancreatic, non-small cell lung, ovarian, bladder, neck and head etc. Gemcitabine Hydrochloride exerts its activity through the inhibition of DNA synthesis by chain termination method. Being a potent antitumor agent, Gemcitabine Hydrochloride is not able to maintain an optimum concentration in the body, because of its very short halflife (short infusions 32 to 94 minutes, long infusions 245 to 638 minutes) and highly hydrophilic nature ${ }^{3-4}$. After systemic administration in the body, Gemcitabine hydrochloride is rapidly inactivated to a metabolite 2'deoxy- 2', 2'difluoro uridine by cytidine deaminase. The 
major limitations of gemcitabine Hydrochloride is short half-life and strong side effects when administered intravenously. Short half lives are commonly due to fast renal clearance, decreased protein binding and enzymatic degradation. Inherent drawbacks of parenteral Gemcitabine Hydrochloride administration warrant an alternative drug delivery system ${ }^{5}$. Solid Lipid Nanoparticles offer great promise to improve therapeutic effectiveness and safety profile of the conventional form of cancer chemotherapy. Hence in the present work, an attempt is being made to provide an alternative colloidal drug delivery system for gemcitabine hydrochloride in the form of Solid lipid nanoparticles. Quality by Design is the modern approach for quality of pharmaceuticals. The aim of pharmaceutical development is to design a quality product and its manufacturing process to consistency deliver the intended performance of the product. The information and knowledge gained from pharmaceutical development studies and manufacturing experience provide scientific understanding to support the establishment of the design space, specification, and manufacturing controls.

\section{MATERIALS AND METHOD:}

\section{Materials:}

Gemcitabine Hydrochloride was obtained as a gift sample from Renuka Raw Pharma (Mumbai), India. All over chemicals were purchased from Merck Research Lab., Fine Chem Industries, Mumbai, India.

\section{Methods:}

Preformulation Studies:
The drug substance of Gemcitabine Hydrochloride and excipients were characterized for their identity and purity. The following studies were performed:

Determination of $\lambda_{\max }$ of Gemcitabine Hydrochloride in PBS (PH 7.4):

Standard stock solution containing Gemcitabine Hydrochloride was prepared by dissolving $10 \mathrm{mg}$ of Gemcitabine Hydrochloride in $100 \mathrm{ml}$ Phosphate Buffer $\mathrm{pH} 7.4$ in volumetric flask. A solution containing 10 $\mu \mathrm{g} / \mathrm{ml}$ of Gemcitabine Hydrochloride was scanned in the range of $200-400 \mathrm{~nm}$.

\section{Compatibility Studies}

Compatibility of the Gemcitabine Hydrochloride with lipids used to formulate SLN was established by FTIR spectral analysis. FTIR Spectral analysis of Gemcitabine Hydrochloride, individual lipids and combination of Gemcitabine Hydrochloride and lipids was carried out to investigate the changes in chemical composition of the drug after combining it with the excipients. Compatibility study was carried out on Fourier Transform Infrared spectrometer.

\section{Design of Experiment by Quality by Design (QBD)}

Quality by design (QBD) principles was applied to gain an understanding of formulation of SLN. The following attributes were identified:

\section{Quality Target Product Profile (QTPP) for the Solid} Lipid Nanoparticles

As per the ICH guidelines Q8 QTTP were defined on the basis of properties of drug substance ${ }^{10}$. Following QTTP parameters of Gemcitabine Hydrochloride loaded SLN were considered to be important as described in Table No. 1.

Table 1: Quality Target Product Profile (QTPP) for SLN

\begin{tabular}{|l|l|l|}
\hline \multicolumn{1}{|c|}{ QTPP Elements } & \multicolumn{1}{c|}{ Target } & \multicolumn{1}{c|}{ Justification } \\
\hline Dosage Form & Freeze dried SLN & SR product required SLN dosage form \\
\hline Dosage design & Sustained Release SLN & Give better effect and acceptable to patient \\
\hline Route of Administration & Parenteral & Most preferred route of administration for this drug \\
\hline
\end{tabular}

\section{Critical Quality Attributes (CQA)}

Table No. 2 summarizes the quality attributes of SLN and indicates which attribute were classified as drug product critical quality attributes (CQAs) ${ }^{10}$.

Table 2: Critical Quality Attributes (CQA) of SLN

\begin{tabular}{|l|l|l|l|l|}
\hline $\begin{array}{c}\text { Quality Attributes of the } \\
\text { Drug Product }\end{array}$ & \multicolumn{1}{|c|}{ Target } & $\begin{array}{l}\text { Is this a } \\
\text { CQA? }\end{array}$ & \multicolumn{1}{c|}{ Justification } \\
\hline $\begin{array}{l}\text { Physical } \\
\text { Attributes }\end{array}$ & Appearance & $\begin{array}{l}\text { Color should be acceptable, } \\
\text { odour and taste should be } \\
\text { masked }\end{array}$ & $\begin{array}{l}\text { No } \\
\text { linked to safety and efficacy. Therefore they } \\
\text { are not critical. }\end{array}$ \\
\cline { 2 - 5 } & Size & $\begin{array}{l}\text { Size of the SLN should be } \\
\text { in Nanometer range }\end{array}$ & $\begin{array}{l}\text { Small size of the SLN is responsible for its } \\
\text { prolonged release of action. Therefore it } \\
\text { was considered as CQA. }\end{array}$ \\
\hline$\%$ Entrapment Efficiency & $70-90 \%$ & $\begin{array}{l}\text { \%EE is critical while adjusting the dose of } \\
\text { the formulation }\end{array}$ \\
\hline
\end{tabular}




\section{Risk Assessment:}

A risk assessment of the drug substance attributes was performed to evaluate the impact of each attribute could have on the drug product CQAs. The relative risk that each attribute presents was ranked as high, medium or low.

Initial Risk Assessment Related to Formulation Development:

Table 3: Initial Risk Assessment of Formulation Variables

\begin{tabular}{|c|c|c|c|}
\hline \multirow{2}{*}{ Drug Product CQAs } & \multicolumn{3}{|c|}{ Formulation Variables } \\
\cline { 2 - 4 } & Concentration of GMS & $\begin{array}{c}\text { Concentration of Tween 80: } \\
\text { Sodium Taurocholate }\end{array}$ & Sonication Time \\
\hline Particle Size of SLN & High & High & High \\
\hline \%EE & Low & Low & Low \\
\hline
\end{tabular}

Table 4: Justification for the Initial Risk Assessment of Formulation Variables

\begin{tabular}{|c|c|l|}
\hline Formulation Variables & Drug Product CQAs & \multicolumn{1}{c|}{ Justification } \\
\hline \multirow{2}{*}{ Concentration of GMS } & Particle Size & $\begin{array}{l}\text { As the concentration of lipid increases particle size of SLN } \\
\text { increases, hence risk was high. }\end{array}$ \\
\cline { 2 - 3 } & $\%$ EE & $\begin{array}{l}\text { Increase in the concentration of lipid doesn't affect the } \\
\% \text { EE, hence risk was low. }\end{array}$ \\
\hline \multirow{2}{*}{$\begin{array}{c}\text { Concentration of Tween 80: } \\
\text { Sodium Taurocholate }\end{array}$} & Particle Size & $\begin{array}{l}\text { As the concentration of surfactant increases particle size of } \\
\text { SLN decreases, hence risk was High. }\end{array}$ \\
\cline { 2 - 3 } $\begin{array}{c}\text { o EE } \\
\text { increases, hence risk was low. }\end{array}$ \\
\hline
\end{tabular}

Initial Risk Assessment of Drug Product Manufacturing Process:

Risk assessment of the overall drug product manufacturing process was performed to identify the high risk steps that may affect CQAs of final drug product. These variables were then investigated in order to better understand the manufacturing process and to develop a control strategy to reduce the risk of failed batches.

Table 5: Initial Risk Assessment of Drug Product Manufacturing Process of SLN

\begin{tabular}{|c|c|c|}
\hline \multirow{2}{*}{ Drug Product CQAs } & \multicolumn{2}{|c|}{ Process Steps } \\
\cline { 2 - 3 } & High Pressure Homogenization & Probe Sonication \\
\hline Particle Size & High & High \\
\hline \% EE & Low & Low \\
\hline
\end{tabular}

Table 6: Justification for Initial Risk Assessment of Drug Product Manufacturing Process of SLN

\begin{tabular}{|c|c|l|}
\hline Process Steps & Drug Product CQAs & \multicolumn{1}{c|}{ Justification } \\
\hline $\begin{array}{c}\text { High Pressure } \\
\text { Homogenization }\end{array}$ & Particle Size & $\begin{array}{l}\text { Particle size of SLN decreases with increase in sonication time. } \\
\text { Hence, risk was High. }\end{array}$ \\
\cline { 2 - 3 } Probe Sonication & \% EE & Increase in HPH time doesn't affect \% EE, hence risk was low \\
\cline { 2 - 3 } & Particle Size & $\begin{array}{l}\text { Probe sonication time is inversely proportional to particle size of } \\
\text { SLN, hence risk was high. }\end{array}$ \\
\hline \multirow{2}{*}{$\%$ EE } & $\begin{array}{l}\text { Increase in probe sonication time has no significant effect on } \\
\% \text { EE, hence risk was low. }\end{array}$ \\
\hline
\end{tabular}

\section{Construction of Pseudo ternary Phase Diagram}

Phase diagram is needed for systemic study of microemulsion composition. From this, the extent of microemulsion region can be identified and its relation to other phases can be established. The pseudo-ternary phase diagrams were constructed by drop wise addition of double distilled water to homogenous liquid mixture of lipid, surfactant, and co-surfactant by water titration method.
A ratio of surfactant over co-surfactant $(\mathrm{Km})$ i.e. S/Co was chosen and the corresponding mixture (Smix) was made. At desired $\mathrm{Km}$ value $(1: 1,2: 1$, and 3:1).Phase diagrams were constructed to define the extent of the microemulsion regions i.e. proportion in which the three / four essential components must be mixed to form a transparent, clear, single phase, homogeneous and stable microemulsion. 


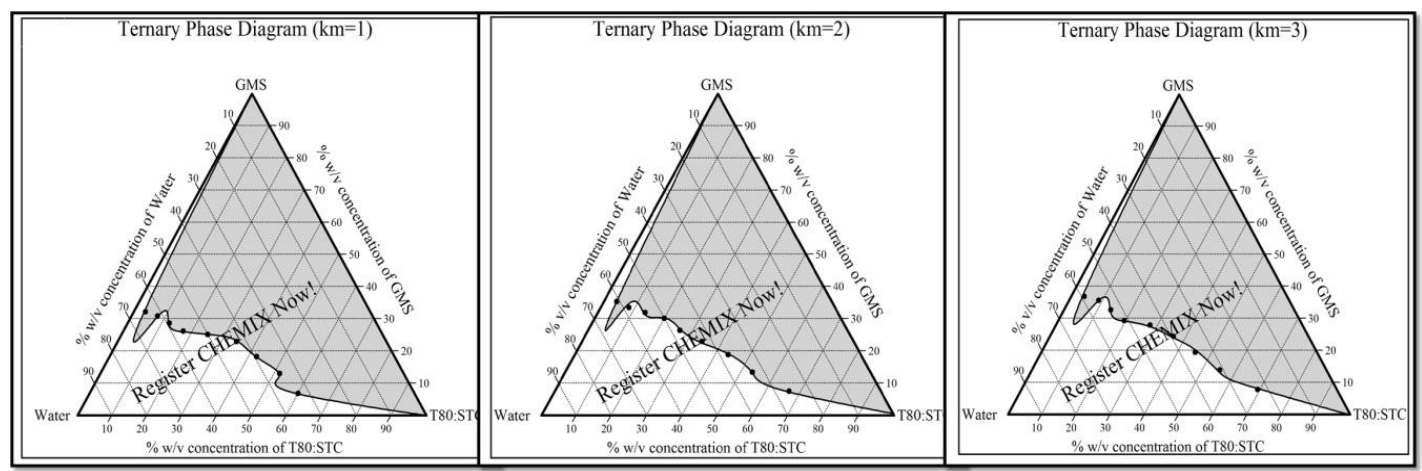

Figure 1: Pseudo-ternary phase diagram of Lipid (GMS) / Smix (Tween 80 and Sodium taurocholate) / Water at $\mathrm{Km}=\mathbf{1}, 2$ and 3.

\section{Formulation of Factorial Batches of SLN:}

The factorial batches of Gemcitabine Hydrochloride loaded SLNs were prepared by applying $3^{2}$ Factorial Design with factor X1(Glyceryl monostearate GMS), X2 (Surfactant concentration: Tween 80: Sodium Taurocholate) as two independent variable at Three levels (-), (0) and (+). The two dependent responses were Y1 (Particle size) and Y2 (Entrapment Efficiency). The coded levels and the actual values of the variables used in this factorial design shown in Table No. 6. Accordingly, total nine formulations were designed and the compositions of different formulations and Formula of the Factorial batches of SLN have been depicted in Table No. 7.

Table 7: $3^{2}$ Factorial Batches

\begin{tabular}{|c|c|c|c|c|}
\hline Factorial Batch & \multicolumn{2}{|c|}{ Coded Form } & \multicolumn{2}{c|}{ Actual Form } \\
\hline Gemcitabine Hydrochloride & X1 & X2 & GMS & Tween 80 \\
\hline SLN1 & + & + & 1.4 & 1.4 \\
\hline SLN2 & 0 & + & 1.0 & 1.4 \\
\hline SLN3 & - & + & 0.6 & 1.4 \\
\hline SLN4 & + & 0 & 1.4 & 1.0 \\
\hline SLN5 & 0 & 0 & 1.0 & 1.0 \\
\hline SLN6 & - & 0 & 0.6 & 1.0 \\
\hline SLN7 & + & - & 1.4 & 0.6 \\
\hline SLN8 & 0 & - & 1.0 & 0.6 \\
\hline SLN9 & - & - & 0.6 & 0.6 \\
\hline
\end{tabular}

Table 8: Formulation composition for the preparation of SLN

\begin{tabular}{|c|c|c|c|c|}
\hline \multirow{2}{*}{ Sr.No } & \multirow{2}{*}{ Formulation } & \multirow{2}{*}{ Drug $(\mathrm{mg})$} & \multicolumn{2}{|c|}{ Composition expressed as \% W/W } \\
\cline { 3 - 5 } & & & Surfactant : Co-Surf & Lipid \\
\hline 1 & SLN1 & 5 & 1.4 & 1.4 \\
\hline 2 & SLN2 & 5 & 1.4 & 1.0 \\
\hline 3 & SLN3 & 5 & 1.4 & 1.4 \\
\hline 4 & SLN4 & 5 & 1.0 & 1.0 \\
\hline 5 & SLN5 & 5 & 1.0 & 0.6 \\
\hline 6 & SLN6 & 5 & 1.0 & 1.4 \\
\hline 7 & SLN7 & 5 & 0.6 & 1.0 \\
\hline 8 & SLN8 & 5 & 0.6 & 0.6 \\
\hline 9 & SLN9 & 5 & 0.6 & \\
\hline
\end{tabular}

Preparation of Gemcitabine Hydrochloride loaded SLN by High shear homogenization (HSH) technique ${ }^{6}$ :

Gemcitabine Hydrochloride loaded batch of SLN was prepared by High shear homogenization method for the preparation of SLN formulation, in the concentration as that of factorial batch using GMS as solid lipid, Tween80: Sodium Taurocholate as surfactant : co(c) 2011-16, JDDT. All Rights Reserved surfactant. In this method, accurately weighed $5 \mathrm{mg}$ of Gemcitabine Hydrochloride was dissolved in distilled water and in a separate vessel GMS, Tween 80 and Sodium Taurocholate were added in to it and heated on a water bath at $60^{\circ} \mathrm{C}$. Once the mixtures reached at $60^{\circ} \mathrm{C}$, the solution of drug was added to the GMS and Tween 80 mixture in a closed vessel under stirring at $3000 \mathrm{rpm}$ using homogenizer. After adding, mixing was continued 
for another 20 minutes to get micro particulate dispersion. After homogenization the dispersions were subjected to probe sonication for further reduction of particle size so as to get nano particulate dispersion. Finally the formulations were stored under refrigeration $\left(2-8^{\circ} \mathrm{C}\right)$ until further use ${ }^{6}$.

\section{Evaluation of Gemcitabine Hydrochloride loaded SLN:}

\section{Optical Microscopy of factorial batches of SLN:}

the prepared SLN dispersion of drugs was determined by using Motic Digital Microscope for Morphology, size and shape. The formulations was placed on the slide and observed under 100X magnification ${ }^{7}$.

\section{\% Entrapment efficiency (\%EE):}

The Gemcitabine Hydrochloride loaded SLN suspension was acidified to $\mathrm{pH} 1.2$ after aggregation of the SLNs solution was immediately separated by centrifugation. Supernatant was withdrawn, filtered with syringe filter. $1 \mathrm{ml}$ of filtrate was diluted to $10 \mathrm{ml}$ with distilled water and absorbance was measured at $268 \mathrm{~nm}$ by UV spectrophotometer. The entrapment efficiency (EE \%) was determined using the following equations ${ }^{7}$ :

Entrapment Efficiency \% $=\frac{\text { Initial Amount Of Drug }- \text { Amount Of Free Drug }}{\text { Initial Amount Of Drug }} x 100$

\section{Optimization of Factorial Batches of SLN:}

All the Factorial batches of SLN formulation were further optimized on the basis of evaluations and with the help of Design-Expert Software.

\section{Freeze Dried of Optimized SLN Batches:}

Free flowing SLN powder was prepared by freeze drying of optimized batch of SLN dispersion. Different parameters were applied in order to obtain free flowing SLN powder. Prior to freeze drying the SLN dispersion was mixed with trehalose $(2.5 \%$ to $10 \%)$ which was used as cryoprotectant. Freeze drying was carried out for $72 \mathrm{~h}$ with parameters. SLN obtained after drying process were in the form of powder. All lyophilized samples were therefore stored at $2-8{ }^{\circ} \mathrm{C}$ in refrigerator.

\section{Particle size analysis and polydispersity index (PI):}

Mean particle size and size distribution of optimized batch of SLN was determined by dynamic light scattering using Malveren zetasizer at room temperature. Before measurement, batches were diluted with filtered double distilled water until the appropriate concentration of particles was achieved to avoid multi-scattering.

\section{Zeta Potential:}

Charge on drug loaded droplet surface was determined using Malveren Zetasizer. Analysis time was kept for 60 s and average ZP, charge and mobility of optimized batch of SLN was determined. All measurements were done at $25^{\circ} \mathrm{C}$

\section{Powder X-ray diffractometry:}

PXRD study reveals information about the crystallographic structure, chemical composition, and physical properties of materials. Freeze dried product of optimized Gemcitabine Hydrochloride loaded SLN batches of the same were irradiated with monochromatised $\mathrm{CuK} \alpha$ radiation and analyzed between $10^{\circ}$ to $70^{\circ}(2 \theta)$. PXRD study was carried out by using $\mathrm{X}$-ray Diffractometer.

\section{Differential Scanning Calorimetry:}

Thermograms of pure drug, freeze dried product of optimized batches of Gemcitabine Hydrochloride loaded SLN of the same were obtained using DSC equipped with an intracooler. Platinum crucible used with alpha alumina powder as reference to calibrate the DSC temperature and enthalpy scale. The powder samples was hermetically kept in the aluminium pan and heated at constant rate $10^{\circ} \mathrm{C}$ per min, over a temperature range of $35^{\circ} \mathrm{C}$ to $250^{\circ} \mathrm{C}$. Inert atmosphere was maintained by purging nitrogen at the flow rate of $150 \mathrm{~mL} / \mathrm{min}$.

\section{Scanning electron microscopy:}

The size, shape and morphology of prepared freeze dried optimized batch of Gemcitabine Hydrochloride loaded SLN were taken in SEM. Samples were coated with platinum using auto fine coater for $75 \mathrm{sec}$. at a $40 \mathrm{~mA}$ operating current. Thickness of coating was less than $25 \mathrm{~nm}$. The images were taken at different magnification and in the following operating conditions: acceleration voltage of $20 \mathrm{kV}$, working distance of $36 \mathrm{~mm}$, sample height in the range of 15 to $18 \mathrm{~mm}$, spot size of 40 to 50 and high vacuum mode.

\section{In vitro drug release studies:}

In vitro release of Gemcitabine Hydrochloride loaded Optimized SLN5 batch was evaluated in PBS pH 7.4 for $24 \mathrm{~h}$ using cellulose membrane dialysis bags having 60 $\mathrm{ml} /$ feet volume capacity, $2.5 \mathrm{~mm}$ average flat width, $16 \mathrm{~mm}$ diameter; $12,000 \mathrm{~g} /$ mole molecular weight cutoff. SLN dispersion was transferred to dialysis tubing and both ends were tightly sealed. The dialysis tube was placed in a beaker containing $100 \mathrm{ml}$ of dissolution medium(PBS pH7.4) and magnetically stirred at 100 rpm. After each sampling the dissolution media were completely replaced with $100 \mathrm{ml}$ of fresh media, to maintain sink conditions, defined as the volume of medium being at least three times higher than that necessary to obtain a saturated solution of $\mathrm{drug}^{7}$. Samples were withdrawn at predetermined time intervals of $1 \mathrm{~h}$ up to $24 \mathrm{~h}$ and analyzed spectrophotometrically using UV visible spectrophotometer at $268 \mathrm{~nm}$.

\section{Accelerated stability studies:}

The accelerated stability studies were carried out according to International Conference on Harmonization (ICH) Q1A (R2) guide lines (FDA, 2003), with the optimized Gemcitabine Hydrochloride loaded SLN. Sealed vials of freshly prepared freeze-dried SLN 5 (3 samples) were placed in stability chamber maintained at $25^{\circ} \mathrm{C} \pm 2{ }^{\circ} \mathrm{C} \& 60 \% \mathrm{RH} \pm 5 \%$.The SLN dispersions subjected to stability test were analyzed over 3 month period for particle size, PDI of nanoparticles with sampling frequency of 1 month $^{7}$. 


\section{In-vitro anticancer activity ${ }^{12-13}$ : Procedure:}

The SRB assay test was used to evaluate the cellular viability of so as to determine the cytotoxic effect of free and entrapped Gemcitabine Hydrochloride on human lung carcinoma cells A-549 (obtained from ACTREC,TATA Memorial Centre Khargar Mumbai). The cell viability was evaluated by determining The cell lines were grown in RPMI 1640 medium containing $10 \%$ fetal bovine serum and $2 \mathrm{mM} \mathrm{L}$-glutamine. For present screening experiment, cells were inoculated into 96 well microtiter plates in $100 \mu \mathrm{L}$ at plating densities as shown in the study details above, depending on the doubling time of individual cell lines. After cell inoculation, the microtiter plates were incubated at $37^{\circ}$ C, $5 \% \mathrm{CO}_{2}, 95 \%$ air and $100 \%$ relative humidity for $24 \mathrm{~h}$ prior to addition of experimental drugs.

Experimental drugs were initially solubilized in dimethyl sulfoxide at $100 \mathrm{mg} / \mathrm{ml}$ and diluted to $1 \mathrm{mg} / \mathrm{ml}$ using water and stored frozen prior to use. At the time of drug addition, an aliquote of frozen concentrate $(1 \mathrm{mg} / \mathrm{ml})$ was thawed and diluted to $100 \mu \mathrm{g} / \mathrm{ml}, 200$ $\mu \mathrm{g} / \mathrm{ml}, 400 \mu \mathrm{g} / \mathrm{ml}$ and $800 \mu \mathrm{g} / \mathrm{ml}$ with complete medium containing test article. Aliquots of $10 \mu \mathrm{l}$ of these different drug dilutions were added to the appropriate microtiter wells already containing $90 \mu \mathrm{l}$ of medium, resulting in the required final drug concentrations i.e. 10 $\mu \mathrm{g} / \mathrm{ml}, 20 \mu \mathrm{g} / \mathrm{ml}, 40 \mu \mathrm{g} / \mathrm{ml}, 80 \mu \mathrm{g} / \mathrm{ml}$.

After compound addition, plates were incubated at standard conditions for 48 hours and assay was terminated by the addition of cold TCA. Cells were fixed in situ by the gentle addition of $50 \mu$ of cold $30 \%$ (w/v) TCA (final concentration, $10 \%$ TCA) and incubated for 60 minutes at $4^{\circ} \mathrm{C}$. The supernatant was discarded; the plates were washed five times with tap water and air dried. Sulforhodamine B (SRB) solution $(50 \mu \mathrm{l})$ at $0.4 \%(\mathrm{w} / \mathrm{v})$ in $1 \%$ acetic acid was added to each of the wells, and plates were incubated for 20 minutes at room temperature. After staining, unbound dye was recovered and the residual dye was removed by washing five times with $1 \%$ acetic acid. The plates were air dried. Bound stain was subsequently eluted with 10 mMtrizma base, and the absorbance was read on an plate reader at a wavelength of $540 \mathrm{~nm}$ with $690 \mathrm{~nm}$ reference wavelength. Percent growth was calculated on a plateby-plate basis for test wells relative to control wells. Percent Growth was expressed as the ratio of average absorbance of the test well to the average absorbance of the control wells $* 100$.

Using the six absorbance measurements [time zero (Tz), control growth $(\mathrm{C})$, and test growth in the presence of drug at the four concentration levels (Ti)], the percentage growth was calculated at each of the drug concentration levels. Percentage growth inhibition was calculated as: [Ti/C] x $100 \%$

\section{RESULTS AND DISCUSSION:}

\section{Determination of $\lambda_{\max }$ of Gemcitabine Hydrochloride in PBS (PH 7.4):}

The absorbance maximum was found to be at $268 \mathrm{~nm}$.

\section{Compatibility Studies:}

Compatibility studies shows no any significant changes were observed in the spectra as shown in figure No. 2

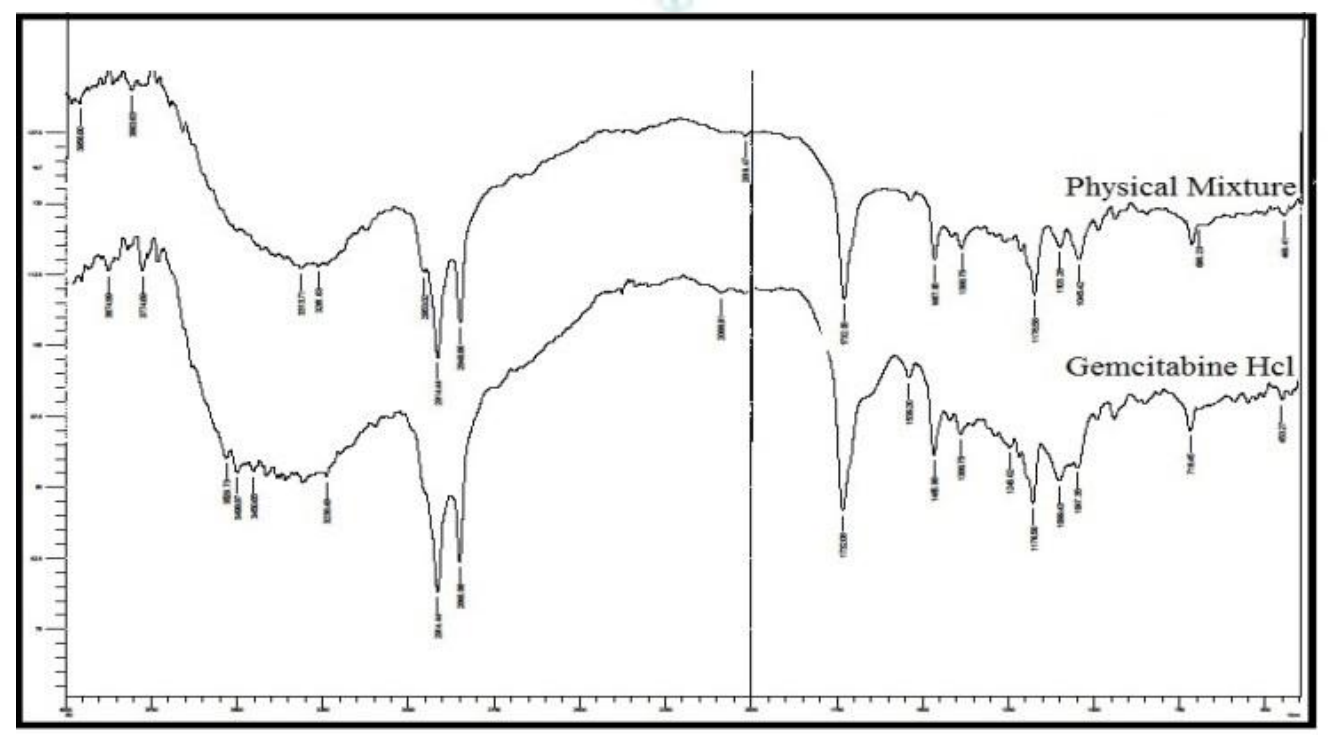

Figure 2: FTIR Overlay spectra of Gemcitabine Hydrochloride \& Physical Mixture 
Optical Microscopy of factorial batches of SLN:

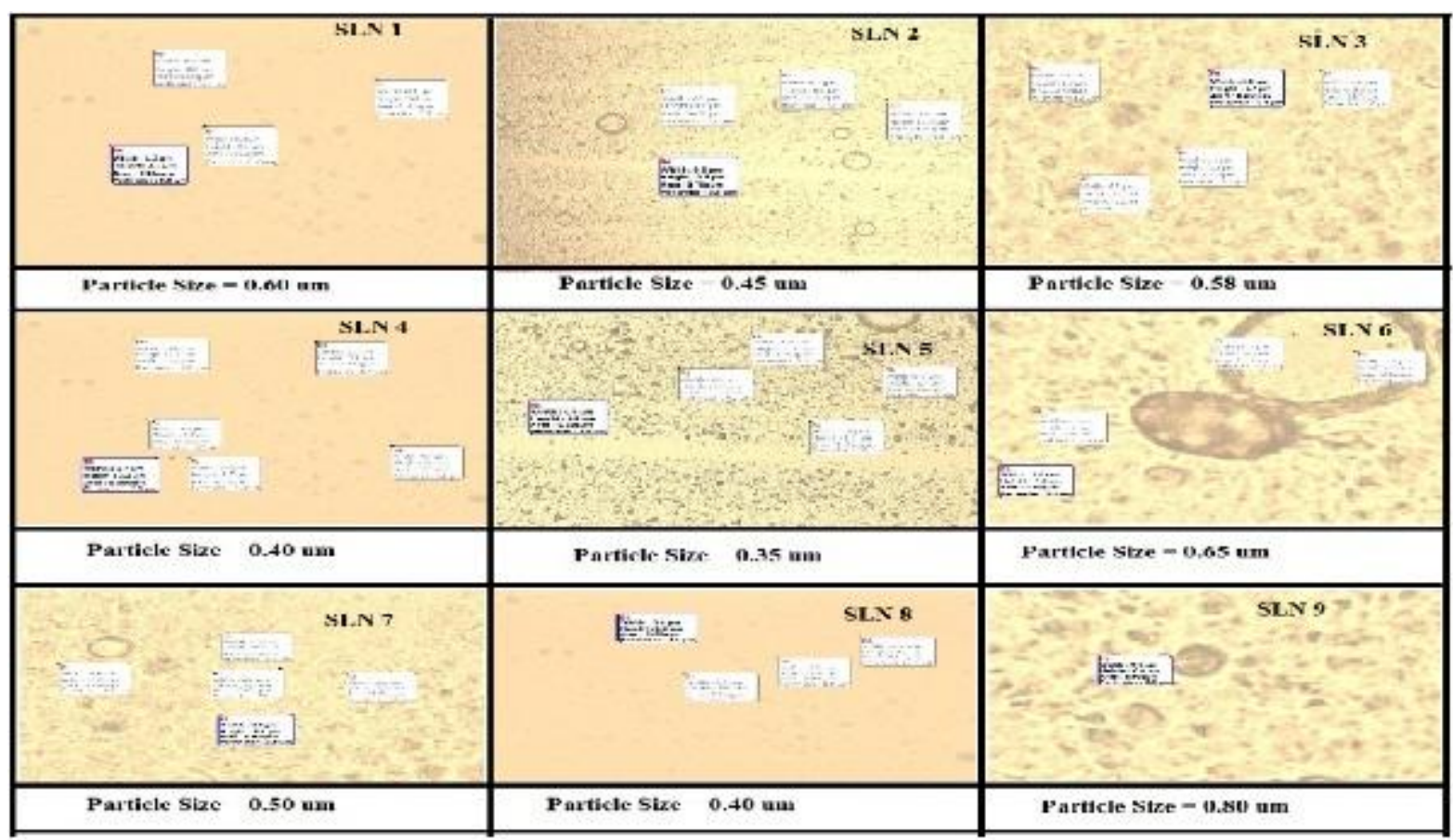

Figure 3: Droplet Size Determination of Gemcitabine Hydrochloride SLN Factorial Batches by Motic Image Plus

Analysis of results indicates that the particle was spherical in shape and size range was $0.35 \mu \mathrm{m}$ to $0.80 \mu \mathrm{m}$. As the lipid load was increased particle size was also increased but surfactant concentration played important role in maintaining particle size in submicron range as shown in figure No. 3 .

$\%$ Entrapment efficiency (\%EE):

Table 9: \% Entrapment efficiency of factorial batches of SLN

\begin{tabular}{|c|c|}
\hline Batch Code & Entrapment efficiency (\%) \\
\hline SLN1 & $39.16 \pm 0.69$ \\
\hline SLN2 & $46.57 \pm 0.11$ \\
\hline SLN3 & $57.93 \pm 0.47$ \\
\hline SLN4 & $48.8 \pm 0.25$ \\
\hline SLN5 & $76.87 \pm 0.41$ \\
\hline SLN6 & $59.45 \pm 1.29$ \\
\hline SLN7 & $68.41 \pm 1.29$ \\
\hline SLN8 & $62.14 \pm 1.29$ \\
\hline SLN9 & $66.70 \pm 1.29$ \\
\hline
\end{tabular}

$\%$ Entrapment efficiency of batches under investigation was in the range of $39.16 \pm 0.69$ to $76.87 \pm 0.41 \%$, shown in Table No. 9. Batch SLN 5 showed highest entrapment efficiency $76.87 \pm 0.41 \%$ whereas, SLN1 showed lowest \% Entrapment efficiency $39.16 \pm 0.69 \%$.

\section{Optimization of the Factorial Batches of SLN:}

A $3^{2}$ randomized full factorial design was utilized in the present study. The different independent variables include: GMS (A), Tween80: Sodium taurocholate (B) concentration. The batches were evaluated and the effect of individual variable was studied according to the response surface methodology. The dependent response includes Particle Size (Y1) and Entrapment Efficiency (Y2). To describe the response surface curvature, the design was evaluated by quadratic model, which bears the following equations.

Particle Size $=2.20-0.30 * \mathrm{~A}[1]+3.466 \mathrm{E}-017 * \mathrm{~A}[2]-$ $0.50 * \mathrm{~B}[1]-0.067 * \mathrm{~B}[2]$

The equation presents a positive effect of GMS (Factor A) concentration and a negative effect of Surfactant (Factor B) concentration on particle size, indicating an increase in particle size as the concentration of GMS increases and decrease in particle size as the concentration of Surfactant increases. The combined effect of X1 \& X2 indicates significant effect on particle size.

\% $\mathbf{E E}=82.05+0.74 * \mathrm{~A}[1]+2027 * \mathrm{~A}[2]+2071 * \mathrm{~B}[1]$

The equation presents a positive effect of GMS (Factor A) and Surfactant (Factor B) concentration on \%EE, indicating an increase in $\% \mathrm{EE}$ as the concentration of GMS and concentration of Surfactant increases. The combined effect of A \& B indicates significant effect on particle size.

\section{Response Surface Analysis:}

3- D response surface plots for variables Y1 (Particle size) and Y2 (\%EE) are shown in Figures 4 and 5.

The response surface plot indicates that for $0.35 \mu \mathrm{m}$ Particle size, the concentrations of GMS and Tween80: STC are $1 \mathrm{gm}$ and $1 \mathrm{gm}$ respectively. It shows that Particle size decreases as the concentration of Tween 80 : STC increases, and particle size increases with increase in the concentration of GMS. 


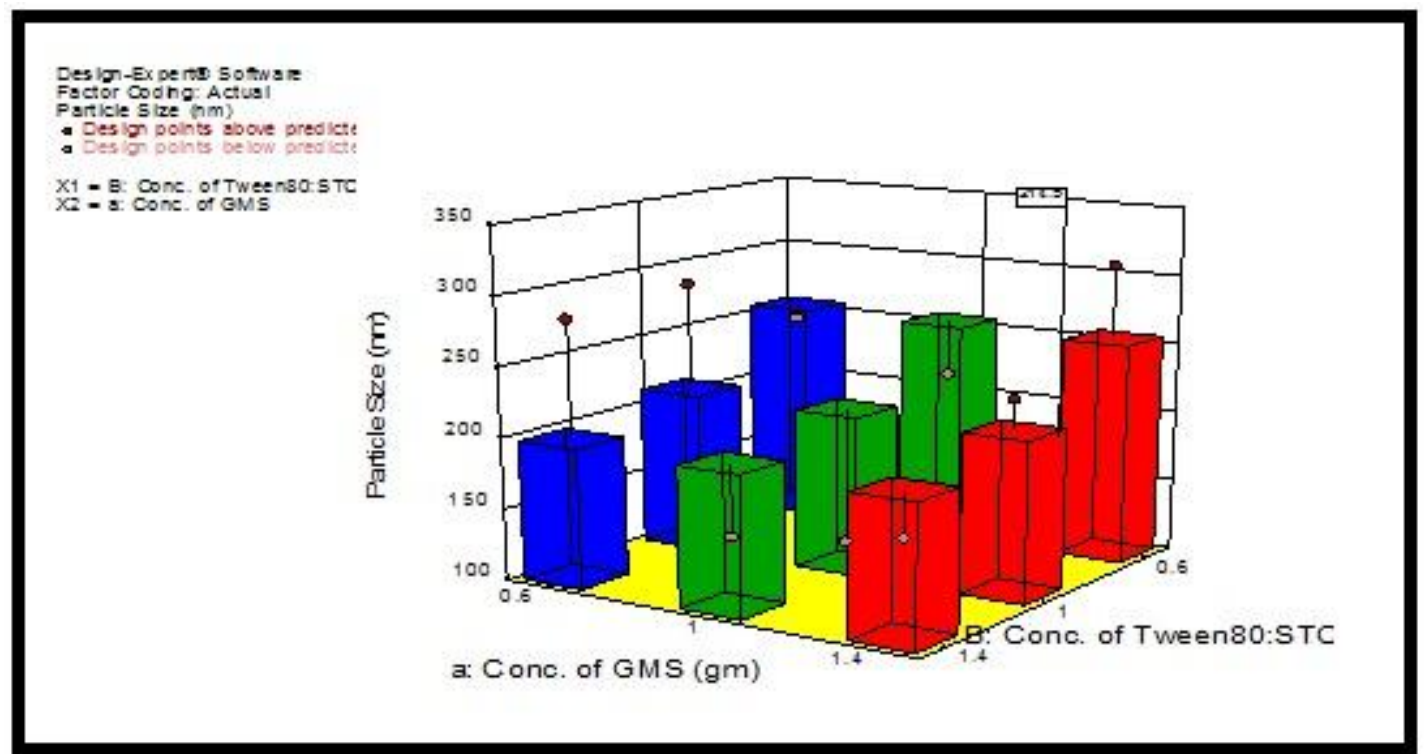

Figure 4: Response Surface Plot (3D Surface Plot) showing Effect of Formulation Variables on Particle Size (Y1) of GEM loaded SLN

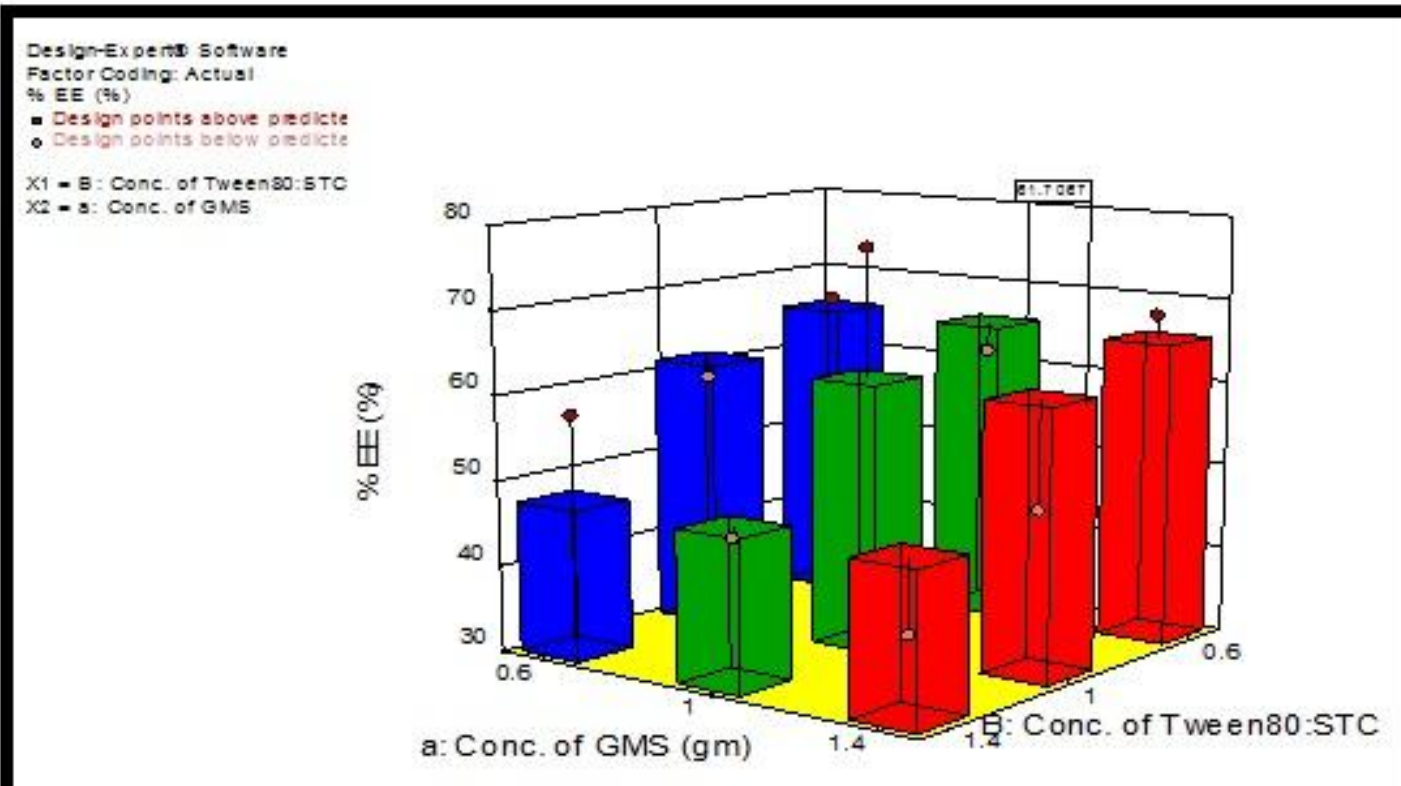

Figure 5: Response Surface Plot (3D Surface Plot) showing Effect of Formulation Variables on \% Entrapment Efficiency (Y2) of GEM loaded SLN

The response surface plot indicates that for $61.7067 \%$ Entrapment Efficiency, concentrations of GMS and Tween80: STC are $1 \mathrm{gm}$ and $1 \mathrm{gm}$ respectively.

It shows that \% Entrapment Efficiency increases as the concentration of GMS.

Full Factorial design was used to develop design space in order to optimize and evaluate the effects of the CPPs (material attributes) on the CQAs, using the Design expert software. The factorial batches were evaluated and the effect of individual variable was studied according to the response surface methodology.

The process was optimized for dependent variables Y1 (Particle size) and Y2 (Entrapment Efficiency). Using the polynomial equations, the optimized formulation was obtained from the surface response counter plot. The optimized formula was obtained by targeting Y1 between the range of 0.35 to $0.80 \mu \mathrm{m}$ for Gemcitabine Hydrochloride respectively and, Y2 between the range 39.16 to $76.87 \%$ for Gemcitabine Hydrochloride. The optimized batch obtained out of the 9 batches, results was determined and the results of optimized formula were compared with the predicted values in Table No. 10 that indicates good relationship between experimental and predicted values confirming the practicability and validity of the model for both the Gemcitabine Hydrochloride loaded SLN. 
Table 10: Comparison between the Experimented and Predicted Values for Most Probable Optimal Formulations

\begin{tabular}{|c|c|c|}
\hline \multirow{2}{*}{$\begin{array}{c}\text { Dependant } \\
\text { Variables }\end{array}$} & \multicolumn{2}{|c|}{ Optimized SLN Formulation of Gemcitabine HCl } \\
\cline { 2 - 3 } & Experimental values & Predicted values \\
\hline Particle Size & $0.35 \mu \mathrm{m}$ & $0.39 \mu \mathrm{m}$ \\
\hline$\% \mathrm{EE}$ & $76.87 \%$ & $61.70 \%$ \\
\hline
\end{tabular}

The software design expert 9 and results suggested SLN 5 as an optimized batch, hence the concentration of batch SLN 5 batch was selected for final formulation with $1 \mathrm{gm}$ of GMS, $1 \mathrm{gm}$ of Tween80: Sodium taurocholate and for Gemcitabine Hydrochloride loaded SLN.

Particle size analysis and polydispersity index (PI):
Figure No. 6 indicates that nanoparticles are of 168.6 $\mathrm{nm}$ size. The mean particle size diameter/Z-average of Gemcitabine Hydrochloride loaded SLN was found to be126.1nm size respectively. PDI shows the particle size distribution. PDI of Gemcitabine Hydrochloride loaded SLN was obtained as 0.598 for optimized colloidal nanoparticle dispersion of SLN.

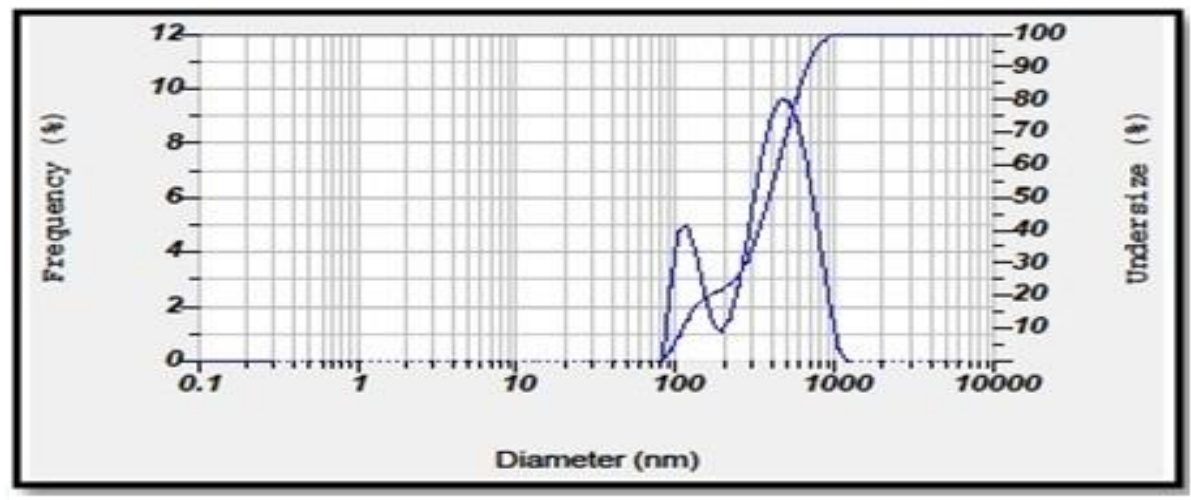

Figure 6: Particle Size Distribution by Intensity of Optimized Batch of Gemcitabine Hydrochloride loaded SLN

\section{Zeta Potential:}

Zeta potential of optimized formulations of Gemcitabine Hydrochloride loaded SLN was found to be $-28.9 \mathrm{mV}$ respectively (Figure No. 7.) which indicated good stability

\section{$\%$ Entrapment efficiency (\%EE)}

The \% Entrapment Efficiency of optimized batch of Gemcitabine Hydrochloride loaded SLN was found to be $74.83 \%$ respectively. There was very less difference in $\% \mathrm{EE}$ as compared to the SLN 5 factorial batch (76.87 respectively).

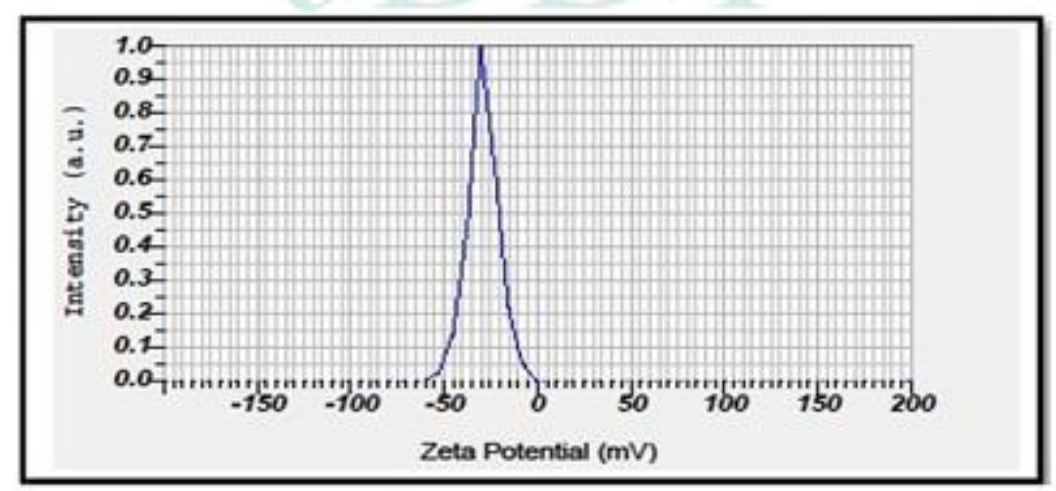

Figure 7: Zeta Potential of Optimized Batch of Gemcitabine Hydrochloride loaded SLN

\section{Powder X-ray diffractometry:}

In PXRD studies, the diffractogram of a freeze dried optimized batch was analyzed to know any changes in crystallinity of drug and excipients in the batches. X-ray diffraction analysis was performed to determine whether the entrapped Gemcitabine Hydrochloride existed in the less crystalline state or the more amorphous state. Sharp peaks in X-ray diffraction spectra indicate a crystalline structure. 


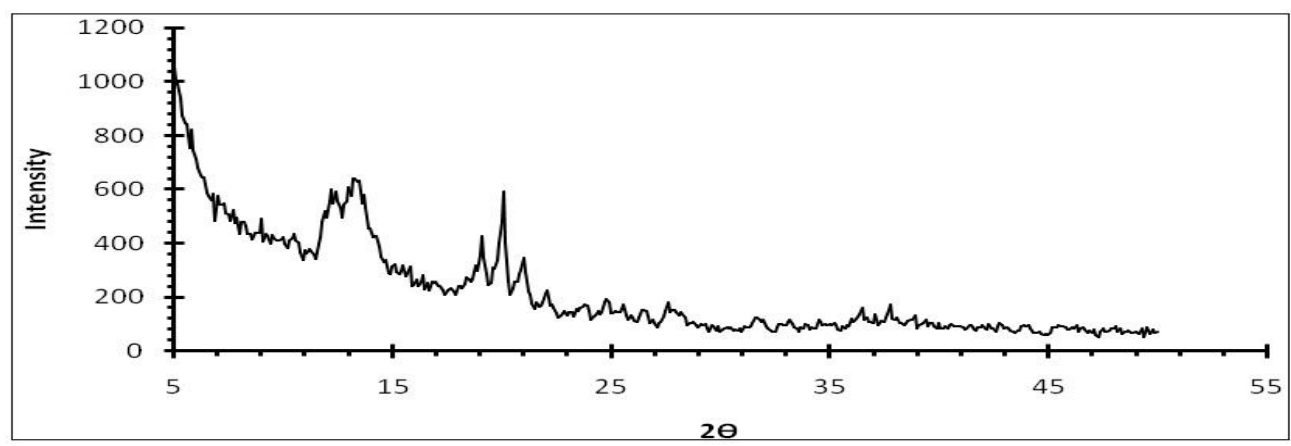

Figure 8: PXRD spectra of Freeze dried batch of Gemcitabine Hydrochloride loaded SLN 5

\section{Differential scanning Calorimetry:}

The DSC spectra of pure Gemcitabine Hydrochloride shows sharp endothermic peak at $286.0^{\circ} \mathrm{C}$. The DSC of freeze dried optimized SLN batch shows shifting of endothermic peak at $278.41^{\circ} \mathrm{C}$ shows in figure No. 9 .

\section{Scanning electron microscopy:}

SEM photographs of freeze dried SLN5 batch as shown in Figure No.10. at different magnification reveals that the particles are nearly spherical in shape with a smooth surface and particles are in nanometric range.

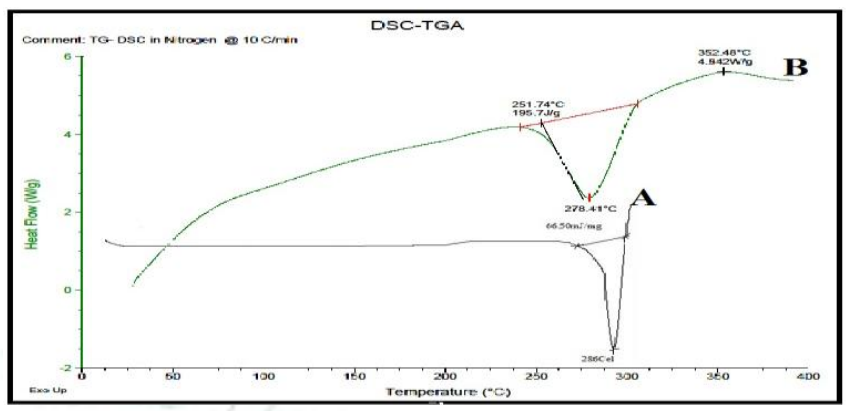

Figure 9: DSC of Gemcitabine Hydrochloride (A) \& freeze dried of optimized batch of Gemcitabine Hydrochloride loaded SLN (B).
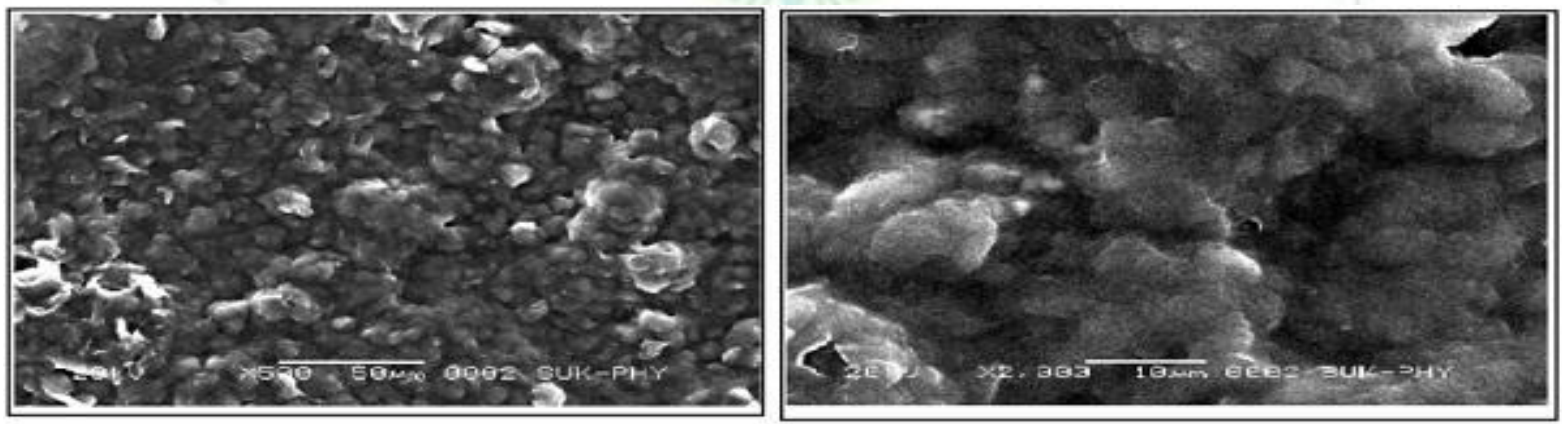

Figure 10: SEM photograph of freeze dried optimized batch of Gemcitabine Hydrochloride loaded SLN product at different magnification.

\section{In vitro drug release studies:}

Significant variation in the release rate was observed in prepared optimized SLN batch. Results reveal initial burst release in first $2 \mathrm{~h}$. for SLN5 batch, where nearly 4-16\% of drug was released which may be due to drug adsorbed at the surface of nanoparticles or precipitated in the superficial lipid matrix. Drug release in later stage was continuous and slow indicating that the drug release rate was following diffusion from the rigid matrix structure. However, it was also observed that any change in concentration of surfactant and lipid load also altered the percentage release from all the formulations.

Initial fast, later slow release of the Gemcitabine Hydrochloride loaded SLN 5 suggests drug enriched shell with core shell model. Method of preparation applied for preparing SLN is responsible for formation of drug enriched shell of SLN 5. During preparation partitioning of drug might have taken place into water phase at high temperature which upon cooling, lipid precipitated first, forming a practically drug free lipid core due to phase separation with drug rich lipid shell. The drug re-partitions into the remaining liquid-lipid phase and drug concentration in the outer shell increasing gradually. After $24 \mathrm{hrs}$ drug release was found to be $63.13 \%$ as shown in figure No. 11 .

\section{Accelerated stability studies:}

The results reported in Table No.11 indicate small increase in particle size and PI of SLN in the dispersion. There was no physical change such as precipitation of lipid and color. Prepared dispersion of SLN5 was stable during accelerated stability study. 


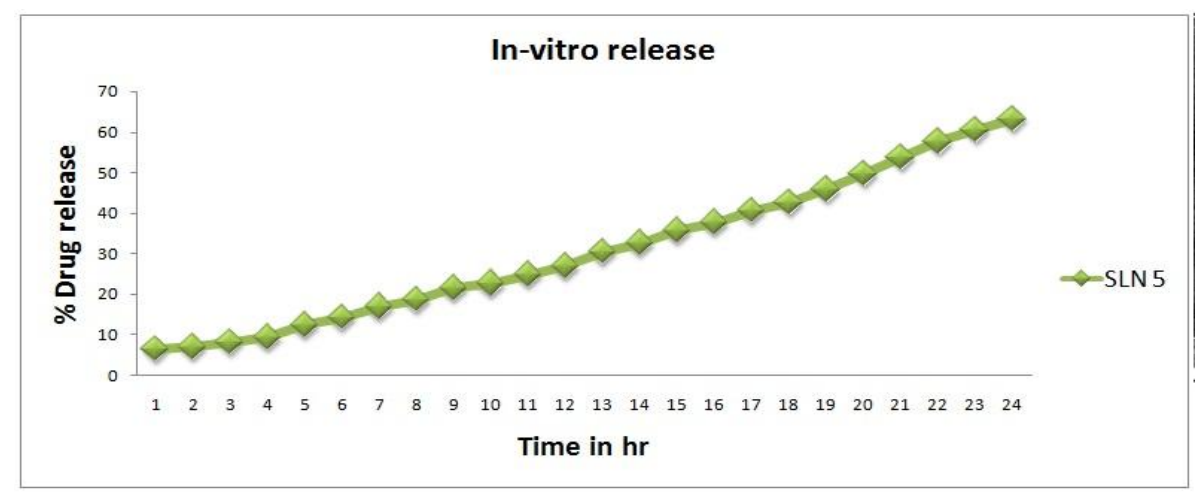

Figure 11: Average release of Gemcitabine from optimized SLN 5 batch

\section{In-vitro anticancer activity:}

Biological efficacy of Gemcitabine Hydrochloride entrapped in SLN5 was tested on human lung carcinoma cells (A-549) by using SRB assay. Empty SLN were used to evaluate possible toxic effect of the carrier on human lung carcinoma cells. After in incubation free Gemcitabine Hydrochloride elicited little cytotoxic effect at the investigated concentrations on lung carcinoma cells, which presents a viability of about $15.3 \%$ to $27.0 \%$. A significant improvement of anticancer activity with respect to the free drug was obtained by using Gemcitabine Hydrochloride loaded SLN. The SLN formulation showed a dose-dependent anticancer activity on human lung carcinoma cells. A significant difference was observed between free drug and SLN formulation at a concentration of $80 \mu \mathrm{g} / \mathrm{ml}$ i.e. cell viability is $15.3 \%$ \& $18.1 \%$ respectively after $24 \mathrm{~h}$ incubation. Lung carcinoma cells showed an improvement of efficacy of SLN formulation over the free drug. The improvement of Gemcitabine anticancer efficiency on lung carcinoma cells provided by SLN formulation suggests the protective and long circulation properties of it.

Table 11: Change in particle size and PI of SLN in the dispersion during stability study

\begin{tabular}{|c|c|c|c|c|}
\hline $\begin{array}{c}\text { Time of } \\
\text { Sampling } \\
\text { (month) }\end{array}$ & \multicolumn{2}{|c|}{ Particle Size } & \multicolumn{2}{c|}{ PI } \\
\cline { 2 - 5 } & Zero time & $\begin{array}{c}\text { After sampling } \\
(\mathbf{n m})\end{array}$ & Zero time & After sampling (nm) \\
\hline 1 & 126.1 & 152.6 & 0.598 & 0.612 \\
\hline 2 & 126.1 & 154.7 & 0.598 & 0.634 \\
\hline 3 & 126.1 & 155.8 & 0.598 & 0.623 \\
\hline
\end{tabular}

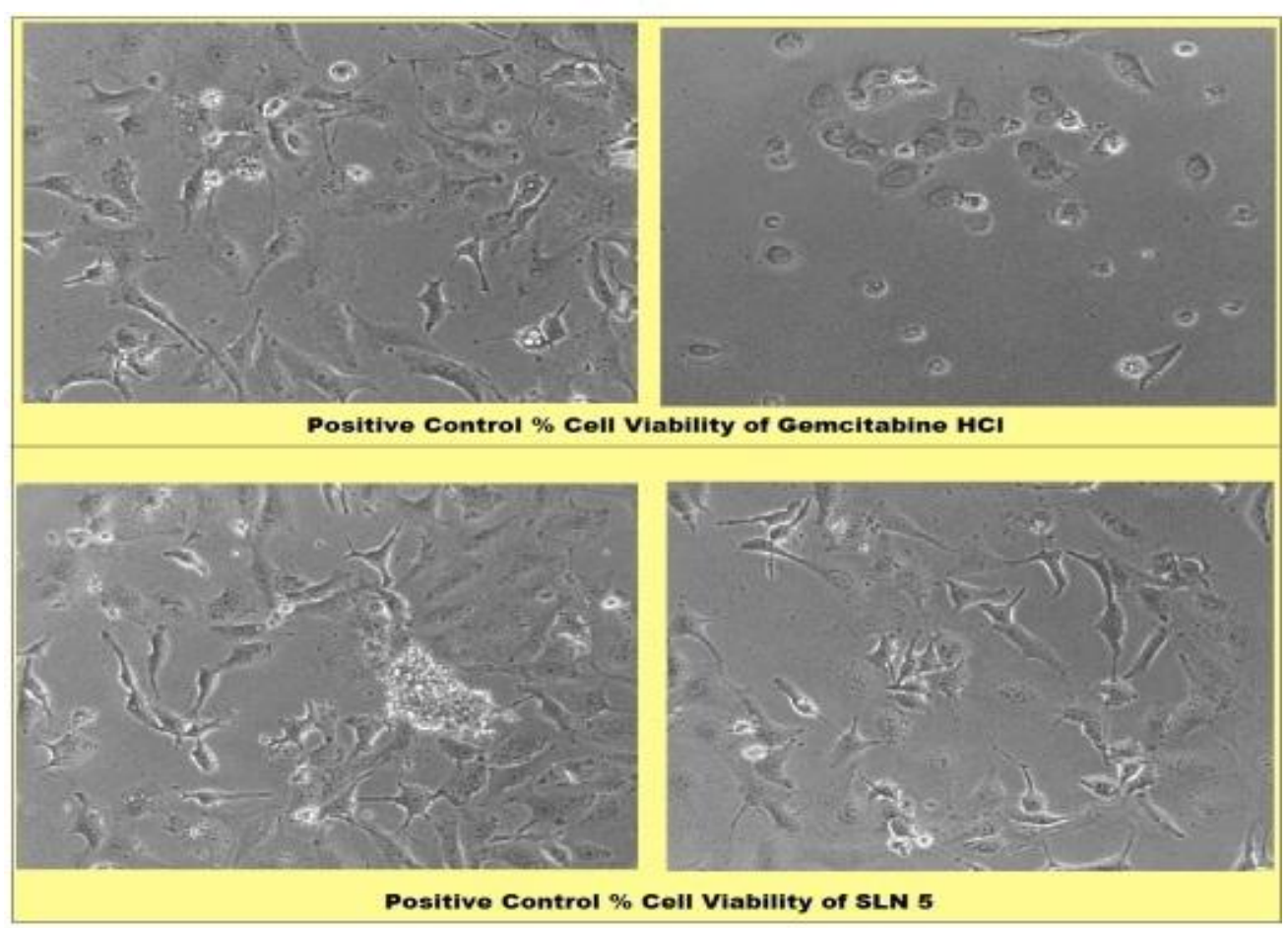

Figure 12: Positive Control Growth Activity on Human Lung Cancer Cell A-549 


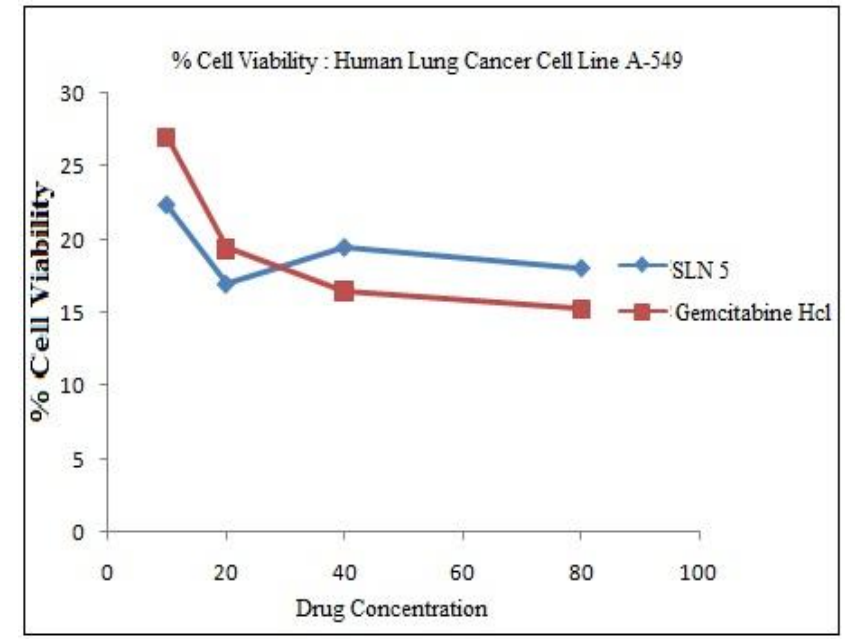

Figure 13: Dose-dependent anticancer activity of free drug, SLN formulations on human lung carcinoma cells by SRB assay

\section{CONCLUSIONS:}

Incorporation of Gemcitabine Hydrochloride in SLN by QBD approach was successfully carried out with significant enhancement in drug entrapment, improved stability and achievement of extended release. Gemcitabine Hydrochloride loaded Solid lipid Nanoparticles were successfully formulated and evaluated to sustain the drug release by by passing the first pass metabolism. Gemcitabine Hydrochloride loaded SLN in the treatment of Human Lung Cancer for prolonged release of action as well as reduced the dose of the drug was achieved. Moreover in vitro anticancer activity has showed remarkable improvement.

\section{ACKNOWLEDGMENTS:}

Author is Thankful to Renuka raw pharma Mumbai for Supplying gift sample of Gemcitabine Hydrochloride, and also thankful to ACTREC Mumbai for helping in Cell line study.

\section{CONFLICTS OF INTEREST:}

No conflicts of interest. Authors alone are responsible for the content and writing of the paper.

\section{REFERENCES:}

1. Mitra S, Mitra AN. Nanoparticulate carriers in drug delivery and targeting. PINSA B68 No. 4, 2002; pp 349360.

2. Abratt RP. Gemcitabine Hydrochloride: Combination of activity and tolerability. Anticancer Drugs, 1995; 6:63-64.

3. Manjunath K, Reddy JS, Venkateswarlu V., Solid lipid nanoparticles as drug delivery systems, Methods Find. Exp. Clin. Pharmacol. 2005; 27:127-144.

4. Müller RH, Mehnert W, Lucks JS, Schwarz C, Zur Mühlen A, Weyhers H, Freitas C, Rühl D, Solid lipid nanoparticles (SLN) - An alternative colloidal carrier system for controlled drug delivery, Eur. J. Pharm. 1995; 41:62-69.

5. Gohla S, Rainer H, MuÈller, Karsten MaÈder, Solid lipid nanoparticles (SLN) for controlled drug delivery - A review of the state of art. Eur. J. Pharm. Biopharm. 2000; 50:161177.

6. Lawrence TS. Radiation sensitizers and targeted therapies, oncology. 2003; 17:23-28.

7. Mokashi AS, Solid lipid nanoparticles of gemcitabine hydrochloride. bentham science publishers 2012; 2:00000000 .

8. Siekmann B, Westesen K. Investigations on solid lipid nanoparticles prepared by precipitation in $\mathrm{o} / \mathrm{w}$ emulsions. Eur. J. Pharm. Biopharm.(1996; 43:104-109.

9. Reddy LH. Couvreur, P.Novel Approaches to deliver gemticabine to cancers. Curr.Pharm. Des., 2008; 14:11241137.

10. Lionberger RA, Lee LS, Lee L, Raw A, Yu LX, Quality by design: Concepts for ANDAs, The AAPS Journal, 2008; 10:268-276.

11. Nadpara NP, Quality By Design (QBD): A complete Review. Int.J.pharm.sci.Rev.Res. 2012; 17(2):04, 20-28.

12. Skehn P, Storeng R, Scudiero A, Monks J, McMohan D, Vistica D, Jonathan TW, Bokesch H, Kenney S, Boyd M R. New colorimetric cytotoxicity assay for anticancer drug screening J. Natl. Cancer Inst. 1990; 82:1107.

13. Vichai V, Kanyawim K. Sulforhodamine B colorimetric assay for cytotoxicity screening Nature Protocols. 2006; 1:1112-1116. 